\title{
High Seroprevalence of Jamestown Canyon Virus among Deer and Humans, Nova Scotia, Canada
}

\author{
Glenn Patriquin, Michael Drebot, Teri Cole, \\ Robbin Lindsay, Emily Schleihauf, \\ B. Lynn Johnston, Kristina Dimitrova, \\ Maya Traykova-Andonova, Angela Mask, \\ David Haldane, Todd F. Hatchette
}

Using residual serum samples from Nova Scotia, Canada, we found that $87.8 \%$ of tested deer and an estimated $20.6 \%$ of the human population were infected with Jamestown Canyon virus. Human seropositivity reached $48.2 \%$ in 1 region. This virus may be an underrecognized cause of disease in Nova Scotia.

Tamestown Canyon virus (JCV), a mosquitoborne arbo$\mathcal{V}$ virus, belongs to the California serogroup (CSG) in the Bunyaviridae family. The primary reservoir host for JCV is considered to be the white-tailed deer, although JCV antibodies have been observed in other mammals, including horses, sheep, and cattle (1). JCV-associated illness among humans is rarely documented; rates of $\leq 0.01$ cases $/ 100,000$ population have been reported in the United States $(2,3)$. Infections can be asymptomatic or associated with a variety of manifestations, including fever, headache, myalgia, weakness, and seizure (4-6).

Evidence of JCV in Atlantic Canada was reported in 1981 when 6 of 289 hunter-killed moose during the 1977-1978 hunting season in Nova Scotia (NS) were seropositive (7). There is no surveillance for JCV in NS, nor is it on the list of diseases notifiable to Provincial Public Health as defined in the NS Health Protection Act (8), but it could be reported as an unusual disease occurance or a disease occuring more frequently than expected. We undertook this study to determine the seroprevalence of JCV in humans and white-tailed deer in this province.

Author Affiliations: Nova Scotia Health Authority, Halifax, Nova Scotia, Canada (G. Patriquin, B.L. Johnston, D. Haldane, T.F. Hatchette); Dalhousie University, Halifax (G. Patriquin, B.L. Johnston, D. Haldane, T.F. Hatchette); Public Health Agency of Canada, Winnipeg, Manitoba, Canada (M. Drebot, R. Lindsay, K. Dimitrova, M. Traykova-Andonova); Nova Scotia Department of Health and Wellness, Halifax (T. Cole); Public Health Agency of Canada, Ottawa, Ontario, Canada (E. Schleihauf, A. Mask).

DOI: https://doi.org/10.3201/eid2401.170484

\section{The Study}

During October 30-November 4, 2009, Public Health Agency of Canada (PHAC) staff or private contractors collected blood from the chest or organs of hunted deer in 2 check stations in NS: Italy Cross (community A) and Lunenburg (community B) (Figure). Hunters visiting a check station collected approximately $10 \%$ of all samples analyzed. Blood samples were collected from 82 deer (40 from community A, 42 from community B). All except 3 of the deer were harvested in zone 102 (https://novascotia.ca/ natr/draws/deerdraw/ddZones.asp\#zone102) in southern NS, which includes community A and community B.

To evaluate prevalence of JCV among humans, we used residual human serum specimens submitted for prenatal screening and testing for cholesterol, electrolytes, or HIV during May 1-August 30, 2012, that had been used in a previous serosurvey (10). We calculated sample size based on estimated seroprevalence of $20 \%$ among the NS population, with precision of $\pm 5 \%$ and the ability to detect a statistically significant difference $(p=0.05)$ between District Health Authority (DHA) 1, DHA 9, and the remaining DHAs (Figure). Because of high seropositivity among hunter-killed deer in DHA 1, humans were oversampled in DHA 1 to facilitate comparisons with other DHAs. We based human population estimates for 2012 on census data from Statistics Canada. We used Stata version 13.0 (StataCorp, College Station, TX, USA) for statistical analysis and used the Stata svy prefix command to incorporate sampling weights to produce estimates representative of the NS population. We stratified serum samples by age, sex, and DHA, with sampling proportionate to the NS population in 10-year age groups for those 10-59 years of age and a 5-year age group for those 60-64 years of age. We used Pearson $\chi^{2}$ and corrected $\chi^{2}$ statistics to test for significant differences based on DHA and sex, respectively. We used logistic regression to test for a significant increasing trend in seroprevalence by age group.

The Research Ethics Board of each DHA approved the serosurvey; 1 board required an opt-out option by publicizing the study and asking patients to self-identify nonparticipation at the time of collection. No patient declined participation.

We shipped the samples to the National Microbiology Laboratory, where serum samples were stored at $-80^{\circ} \mathrm{C}$. 


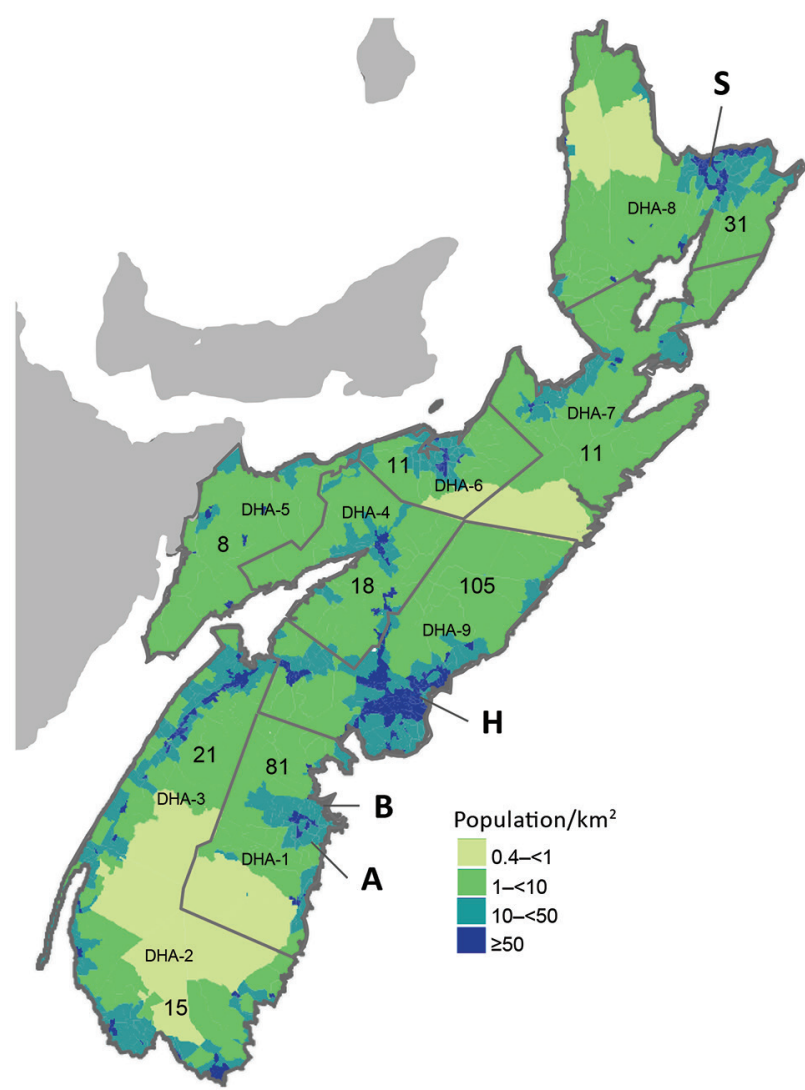

Figure. Population density and boundaries of DHAs in Nova Scotia, Canada, at the time of sample collection from white-tailed deer in 2009 and humans in 2012 for study of Jamestown Canyon virus seroprevalence. $\mathrm{H}$, capital city of Halifax; S, Sydney; A, community A; B, community B. Numbers on map indicate number of human serum samples screened in each DHA. Population density map modified from its original format (9). DHA, District Health Authority.

JCV antibodies in human and deer specimens were determined by using an arbovirus plaque-reduction neutralization assay (PRNT); a titer of $\geq 1: 20$ was considered positive (11). Snowshoe hare virus (SSHV) or JCV and various dilutions of deer serum samples were incubated at $37^{\circ} \mathrm{C}$ for $1 \mathrm{~h}$ in tissue culture media, then added to Vero cell monolayers. After 1 hour of incubation at $37^{\circ} \mathrm{C}$, an agar overlay was added; the plates were incubated in $\mathrm{CO}_{2}$ for 3 days. An overlay containing neutral red was added to visualize plaque formation. Serum samples that inhibited $>90 \%$ of plaque formation relative to virus controls, the highest positive serum dilution of the titration endpoint, were considered positive for viral antibodies. PRNT results were considered positive if the neutralizing antibody titer was $\geq 20$; additional PRNT endpoint titrations were used to discriminate between related California serogroup viruses. Serum samples that demonstrated a 4 -fold or greater difference in PRNT titers between SSHV and JCV were used to identify the virus to which the individual was previously exposed. JCV and SSHV strains used in PRNT assays were NY74-31 and SK75-93, respectively.

JCV antibody titers in samples from 72 of 82 deer ranged from 1:20 to $>1: 1,280$; overall seroprevalence was $87.8 \%$ (95\% CI 78.7\%-94.0\%; Table 1). Measured by using the Fisher exact test, seropositivity did not differ significantly based on sampling location, and JCV exposure did not differ by sex: $87.5 \%(35 / 40)$ of male deer and $91.9 \%(34 / 37)$ of female deer were seropositive (Table 1$)$. Seropositivity increased with age $(75.0 \%$ of immature deer and $93.1 \%$ of adult deer were JCV-positive), but the difference was not statistically significant $(\mathrm{p}=0.0567)$.

Of 301 human serum specimens tested for JCV antibodies, 81 were positive (Table 2). After adjusting for survey design, the estimated overall seroprevalence for JCV in NS was $20.6 \%$ (95\% CI $16.0 \%-25.9 \%)$. The DHA 1 seropositivity of $48.2 \%$ (95\% CI $37.2 \%-59.1 \%$ ) was significantly higher than those of DHAs $2-8$ (combined seroprevalence: $22.6 \%, 95 \%$ CI $15.8 \%-31.4 \%$ ) and that of DHA 9 (seroprevalence 15.2\%, 95\% CI 9.5\%-23.5\% [Table 2]). Estimated seroprevalence was higher for men and boys than for women and girls ( $26.8 \%$ vs. $14.4 \%$, respectively; $p=0.013)$ and increased with age $(p=0.024)$ : $10.8 \%$ were seropositive among those $10-19$ years of age, and 33\% were seropositive among those 60-64 years of age (Table 2).

\section{Conclusions}

In this study, we found that $>20 \%$ of the tested residual serum samples of persons from Nova Scotia had antibody evidence of infection with JCV. The highest seroprevalence was $48 \%$ in specimens tested from 1 of the 9 DHAs. JCV antibodies were found in $88 \%$ of hunter-killed deer, higher than in studies in the United States $(12,13)$.

A seroprevalence rate of $20.6 \%$ in persons living in NS is comparable to that seen in reports of other locations $(14,15)$. The lowest rates of JCV in NS are in DHAs in which the province's 2 most populous cities, Halifax

\begin{tabular}{|c|c|c|c|}
\hline No. white-tailed deer & $\begin{array}{c}\text { No. (\%) } \\
\text { seropositive }\end{array}$ & $\begin{array}{c}\text { No. } \\
\text { seronegative }\end{array}$ & $\mathrm{p}$ value \\
\hline Total, $\mathrm{n}=82$ & $72(87.8)$ & 10 & $\mathrm{NA}^{*}$ \\
\hline $\begin{array}{r}\text { Community } \\
\text { A, } n=40 \\
B, n=42 \\
\end{array}$ & $\begin{array}{l}35(87.5) \\
37(88.1)\end{array}$ & $\begin{array}{l}5 \\
5\end{array}$ & 1.000 \\
\hline $\begin{array}{l}\text { Sex } \\
\text { Male, } n=40 \\
\text { Female, } n=37 \\
\text { Unknown, } n=5\end{array}$ & $\begin{array}{c}35(87.5) \\
34(91.9) \\
3(60.0) \\
\end{array}$ & $\begin{array}{l}5 \\
3 \\
2 \\
\end{array}$ & 0.713 \\
\hline $\begin{array}{l}\text { Age } \\
\text { Adult, } \mathrm{n}=58 \\
\text { Immature, } \mathrm{n}=24\end{array}$ & $\begin{array}{l}54(93.1) \\
18(75.0)\end{array}$ & $\begin{array}{l}4 \\
6\end{array}$ & 0.0567 \\
\hline
\end{tabular}


Table 2. Human Jamestown Canyon virus seropositivity by sex and age, Nova Scotia, Canada

\begin{tabular}{lccc}
\hline Characteristic & No. tested & No. $(\%)$ positive & Adjusted proportion $(95 \% \mathrm{Cl})$ \\
\hline Sex & & & $\mathrm{p}$ value \\
$\mathrm{M}$ & 151 & $51(33.8)$ & $26.8(19.9-35.0)$ \\
$\mathrm{F}$ & 150 & $30(20.0)$ & $14.4(9.3-21.5)$ \\
\hline Age group, y & & & \\
$10-19$ & 43 & $6(14.0)$ & $10.8(4.0-25.8)$ \\
$20-29$ & 54 & $13(24.1)$ & $20.4(11.0-34.5)$ \\
$30-39$ & 52 & $12(23.1)$ & $14.1(6.9-26.7)$ \\
$40-49$ & 60 & $15(25.0)$ & $20.4(1.6-33.3)$ \\
$50-59$ & 61 & $21(34.4)$ & $27.8(17.1-41.7)$ \\
$60-64$ & 31 & $14(45.2)$ & $33.0(17.7-53.0)$ \\
\hline District Health Authority & & & \\
1 & 81 & $39(48.2)$ & $48.2 \dagger(37.4-59.1)$ \\
$2-8$ & 115 & $26(22.6)$ & $22.6 \dagger(15.8-31.4)$ \\
9 & 105 & $16(15.2)$ & $15.2 \dagger(9.5-23.5)$ \\
\hline Total no. & 301 & $81(26.9)$ & $20.6(16.0-25.9)$ \\
*Pearson $\chi^{2}$ for test by DHA; corrected Pearson $\chi^{2}$ for test by sex; logistic regression test for trend by age group. \\
†Adjustment was unnecessary for estimates made by the DHA because weighting was done by this authority. \\
\hline
\end{tabular}

(DHA 9) and Sydney (DHA 8), are located. In addition to correlating JCV seropositivity with geographic location, this study demonstrated associations of seropositivity with male sex and increasing age in both sexes. These findings support prior data that identified increasing age as predictive for JCV infection, reporting an approximate 10 -fold increase in JCV antibodies among persons in Alaska when comparing those $<4$ years of age with those $>65$ years of age $(15)$.

A limitation of this study is the relatively small number of serum samples, which may not represent the population at risk for this zoonotic disease. The use of anonymized residual serum samples did not enable us to collect data on outdoor activities, exposure history, or travel, so we cannot rule out the possibility that exposure to JCV occurred outside the respective DHA.

We provide serologic evidence of JCV infection in humans and deer in NS and suggest that central nervous system infections (e.g., viral encephalitis and viral meningitis) caused by JCV have been unrecognized. Until more is known of JCV's clinical effect in this province, evidence of its circulation should prompt consideration as a possible etiology of aseptic central nervous system disease.

\section{Acknowledgments}

We thank Colleen Jackson, Charles Heinstein, Carol Pelton, and Catherine Roberts for their help in processing the specimens. We also thank the laboratory staff in the regional laboratories across the Province of Nova Scotia.

The Capital Health Research Fund and the Nova Scotia Department of Health and Wellness provided funding.

Dr. Patriquin is a resident in a combined Infectious Diseases and Medical Microbiology program at Dalhousie University in Halifax, Nova Scotia. His research interests include emerging infections and laboratory diagnostics.

\section{References}

1. Goff G, Whitney H, Drebot MA. Roles of host species, geographic separation, and isolation in the seroprevalence of Jamestown Canyon and snowshoe hare viruses in Newfoundland. Appl Environ Microbiol. 2012;78:6734-40. http://dx.doi.org/10.1128/ AEM.01351-12

2. Lindsey NP, Lehman JA, Campbell GL, Staples JE, Fischer M, Yendell SJ; Centers for Disease Control and Prevention (CDC). West Nile virus disease and other arboviral diseases - United States, 2011. MMWR Morb Mortal Wkly Rep. 2012;61:510-4.

3. Lindsey NP, Lehman JA, Staples JE, Fischer M; Division of Vector-Borne Diseases, National Center for Emerging and Zoonotic Infectious Diseases, CDC. West Nile virus and other arboviral diseases-United States, 2013. MMWR Morb Mortal Wkly Rep. 2014;63:521-6.

4. Lowell J, Higgins DP, Drebot M, Makowski K, Staples JE; Centers for Disease Control and Prevention (CDC). Human Jamestown Canyon virus infection-Montana, 2009. MMWR Morb Mortal Wkly Rep. 2011;60:652-5.

5. Huang C, Campbell W, Grady L, Kirouac I, LaForce FM. Diagnosis of Jamestown Canyon encephalitis by polymerase chain reaction. Clin Infect Dis. 1999;28:1294-7. http://dx.doi.org/ $10.1086 / 514789$

6. Grimstad PR, Shabino CL, Calisher CH, Waldman RJ. A case of encephalitis in a human associated with a serologic rise to Jamestown Canyon virus. Am J Trop Med Hyg. 1982;31:1238-44. http://dx.doi.org/10.4269/ajtmh.1982.31.1238

7. McFarlane BL, Embil JA, Artsob H, Spence L, Rozee KR. Antibodies to the California group of arboviruses in the moose (Alces alces americana Clinton) population of Nova Scotia. Can J Microbiol. 1981;27:1219-23. http://dx.doi.org/10.1139/m81-187

8. Her Majesty the Queen in right of the Province of Nova Scotia. Health protection act [cited 2017 Nov 2]. https://novascotia.ca/just/ regulations/regs/hpanotfi.htm

9. Statistics Canada. Population density, 2006 by dissemination area (DA) (map). 2006 Census of Canada. Statistics Canada catalogue no. 92-173-XIE. Released 2008 Jul 23 [cited 2017 May 18]. http://www12.statcan.gc.ca/census-recensement/2011/geo/ map-carte/pdf/thematic/2006/pop/04051419092025_2006_140120 09151401121522051822090523.pdf

10. Hatchette TF, Johnston BL, Schleihauf E, Mask A, Haldane D, Drebot M, et al. Epidemiology of Lyme disease, Nova Scotia, Canada, 2002-2013. Emerg Infect Dis. 2015;21:1751-8. http://dx.doi.org/10.3201/eid2110.141640

11. Beaty BJ, Calisher CH, Shope RS. Diagnostic procedures for viral, rickettsial and chlamydial infections. In: Schmidt NJ, 
Emmons RW, editors. 6th ed. Washington: American Public Health Association; 1989.

12. Murphy RK. Serologic evidence of arboviral infections in whitetailed deer from central Wisconsin. J Wildl Dis. 1989;25:300-1. http://dx.doi.org/10.7589/0090-3558-25.2.300

13. Zamparo JM, Andreadis TG, Shope RE, Tirrell SJ. Serologic evidence of Jamestown Canyon virus infection in white-tailed deer populations from Connecticut. J Wildl Dis. 1997;33:623-7. http://dx.doi.org/10.7589/0090-3558-33.3.623

14. Stansfield SK, Calisher CH, Hunt AR, Winkler WG. Antibodies to arboviruses in an Alaskan population at occupational risk of infection. Can J Microbiol. 1988;34:1213-6. http://dx.doi.org/ 10.1139/m88-213
15. Walters LL, Tirrell SJ, Shope RE. Seroepidemiology of California and Bunyamwera serogroup (Bunyaviridae) virus infections in native populations of Alaska. Am J Trop Med Hyg. 1999;60:806-21. http://dx.doi.org/10.4269/ ajtmh.1999.60.806

Address for correspondence: Todd F. Hatchette, QE II Health Science Center, Division of Microbiology, Department of Pathology and Laboratory Medicine, Rm 315 Mackenzie Bldg, 5788 University Ave, Halifax, NS B3H 1V8, Canada; email: todd.hatchette@cdha.nshealth.ca

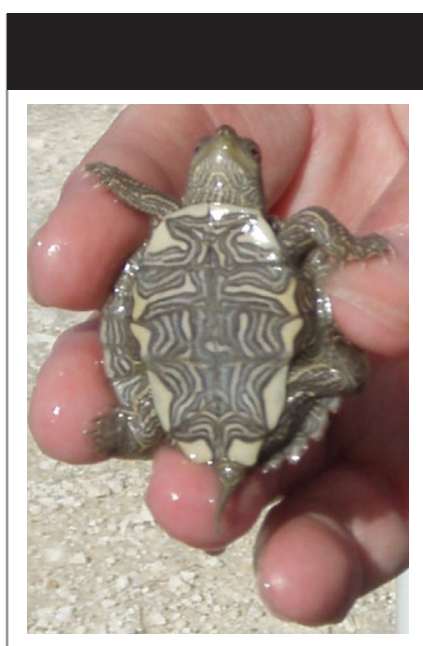

- Turtle-Associated Salmonellosis, United States, 2006-2014

- Pregnancy, Labor, and Delivery after Ebola Virus Disease and Implications for Infection Control in Obstetric Services, United States, 2015

- Response to Middle East Respiratory Syndrome Coronavirus, Abu Dhabi, United Arab Emirates, 2013-2014

- Current Guidelines, Common Clinical Piffalls, and Future Directions for Laboratory Diagnosis of Lyme Disease, United

- Tropheryma whipplei as a Cause of Epidemic Fever, Senegal, 2010-2012

\section{July 2016: Zoonoses}

- Two Linked Enteroinvasive Escherichia coli Outbreaks, Nottingham, United Kingdom, June 2014

- Porcine Bocavirus Infection Associated with Encephalomyelitis in a Pig, Germany

- African Swine Fever Epidemic, Poland, 2014-2015

- Hepatitis E Virus in Dromedaries, North and East Africa, United Arab Emirates and Pakistan, 1983-2015

- Heatwave-Associated Vibriosis, Sweden and Finland, 2014

- Vesicular Disease in 9-Week-Old Pigs Experimentally Infected with Senecavirus A

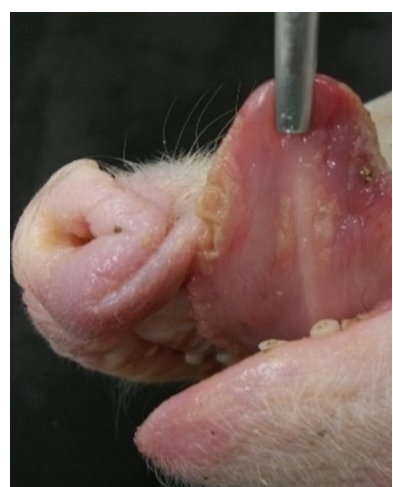

- High Incidence of Chikungunya Virus and Frequency of Viremic Blood Donations during Epidemic, Puerto Rico, USA, 2014

- A Literature Review of Zika Virus

- Senecavirus A in Pigs, United States, 2015

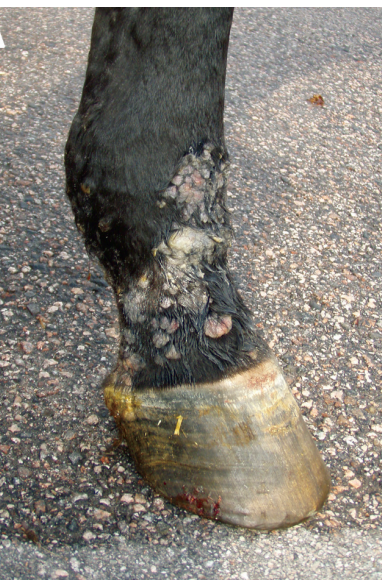

- Outbreak of Vibrio parahaemolyticus Sequence Type 120, Peru, 2009

- Clinical Manifestations of Senecavirus A Infection in Neonatal Pigs, Brazil, 2015

- Infection with Possible Novel Parapoxvirus in Horse, Finland, 2013

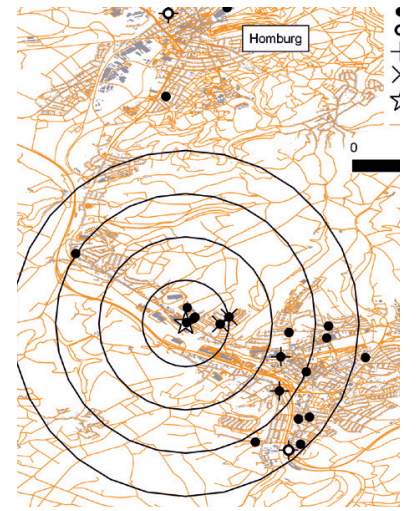

- Travel-Associated Rabies in Pets and Residual Rabies Risk, Western Europe

- Naturally Circulating Hepatitis A Virus in Olive Baboons, Uganda

- Highly Pathogenic Avian Influenza Viruses and Generation of Novel Reassortants, United States, 2014-2015

- Detection and Genomic Characterization of Senecavirus A, Ohio, USA, 2015
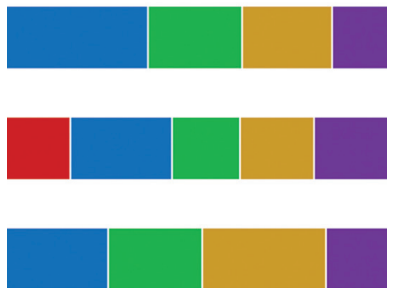